\title{
Herbal preparation (HemoHIM) enhanced functional maturation of bone marrow- derived dendritic cells mediated toll-like receptor 4
}

Sung-Ju Lee ${ }^{1}$, Jong-Jin Kim², Kyung-Yun Kang ${ }^{1}$, Yun-Ho Hwang ${ }^{1}$, Gil-Yeon Jeong ${ }^{1}$, Sung-kee Jo ${ }^{3}$, Uhee Jung ${ }^{3}$, Hae-Ran Park ${ }^{3}$ and Sung-Tae Yee ${ }^{1 *}$

\begin{abstract}
Background: HemoHIM, which is an herbal preparation of three edible herbs (Angelicam gigas Nakai, Cnidium offinale Makino, and Peaonia japonica Miyabe), is known to have various biological and immunological activities, but the modulatory effects of this preparation on dendritic cells (DCs)-mediated immune responses have not been examined previously. DCs are a unique group of white blood cells that initiate primary immune responses by capturing, processing, and presenting antigens to T cells.

Results: In the present study, we investigated the effect of HemoHIM on the functional and phenotypic maturation of murine bone marrow-derived dendritic cells (BMDCs) both in vitro and in vivo. The expression of co-stimulatory molecules (CD40, CD80, CD86, MHC I, and MHC II) and the production of cytokines (IL-1 $\beta$, IL-6, IL-12p70, and TNF-a) were increased by HemoHIM in BMDCs. Furthermore, the antigen-uptake ability of BMDCs was decreased by HemoHIM, and the antigen-presenting ability of HemoHIM-treated mature BMDCs increased TLR4-dependent CD4 ${ }^{+}$and $C D 8^{+} T$ cell responses.

Conclusions: Our findings demonstrated that HemoHIM induces TLR4-mediated BMDCs functional and phenotypic maturation through in vivo and in vitro. And our study showed the antigen-presenting ability that HemoHIM-treated mature BMDCs increase $C D 4^{+}$and $C D 8^{+} T$ cell responses by in vitro. These results suggest that HemoHIM has the potential to mediate DC immune responses.
\end{abstract}

Keywords: Herbal Composition (HemoHIM), Bone Marrow-Derived Dendritic Cells, Toll-Like Receptor 4 (TLR4), CD4 ${ }^{+}$T cells, CD8 ${ }^{+} \mathrm{T}$ cells

\section{Background}

Dendritic cells (DCs) are the immune cells that are responsible for the presentation of antigens to T cells. The main functions of DCs are to capture and present antigens on their surfaces and thus activate other immune cells. DCs are the most potent antigen presenting cells (APCs) [1], originate from the bone marrow, and play a pivotal role in the induction of adaptive immunity as initiators of $\mathrm{T}$ cell responses against pathogens and tumors

\footnotetext{
* Correspondence: sungtae@sunchon.ac.kr

'Department of Pharmacy, Sunchon National University, 255 Joongang-Ro,

Seokhyeon-Dong, Suncheon 549-742, Republic of Korea

Full list of author information is available at the end of the article
}

[2-5]. DCs are found in the peripheral blood of tissues as immature DCs and are classified as immature or mature DCs. Immature DCs activate T cells weakly but efficiently capture antigens associated with pathogens, bacteria, tumors, and inflammatory cytokines and then begin to mature and migrate to lymph nodes [3, 5-7]. Mature DCs have lower antigen uptake abilities than immature DCs but express higher levels of co-stimulatory molecules and major histocompatibility complex class (MHC) I and II on their surfaces $[1,8]$. These cells play key roles in the antigen-specific $\mathrm{T}$ cell responses that are required to initiate adaptive immune responses $[2,3,9]$. In particular, mature DCs induce the activation of 
helper-T cells, cytotoxic- $\mathrm{T}$ cells and cell-mediated immune responses and enhance the anti-tumor effects of cytotoxic-T cells [10]. Recent research reveals the development of DC-based anti-tumor immunotherapy, which is driven by the strong interaction between DCs and T cells, whereby DCs present tumor antigens via MHC I and $\mathrm{MHC}$ II and thus activate tumor-specific- $\mathrm{CD} 8^{+}$and $\mathrm{CD}^{+} \mathrm{T}$ cells [10-12]. Like APCs and other immune cells, DCs express specific repertoires of Toll-like receptors (TLRs), which are capable of recognizing microbial components [7, 10, 13], binding to corresponding ligands, and triggering signaling pathways that induce DC activation [7, 10, 13]. TLRs have been reported to be the key receptors responsible for recognizing specific components of antigens [14]. Of the various TLRs, TLR2 and TLR-4 are particularly important markers of DC activation [15-17], and participate in innate defense against bacterial infections [15, 18-20]. Furthermore, these receptors have been implicated in the activation of DCs by exogenous and endogenous adjuvants [12], and TLR-4 usually induces Th1 activation. [10].

HemoHIM is a well-known herbal mixture that consists of consisting of Angelica Radix, Cnidii Rhizoma, and Paeonia Radix [21-31] and has been reported to inhibit various activities of human mast cells [23, 24], to increase the secretion of IFN- $\gamma$ and IL-2, to decrease the secretion of IL-4 by the spleen and lymphocytes [24, 25], to improve immune function $[21,24]$, to exert antiinflammatory effects on carrageenan-induced edema [21], to ameliorate oxidative stress, such as stress induced by irradiation [26], and to affect the activation of immune cells [27]. In addition, HemoHIM has been reported to act as an immune-modulatory agent [28-30], to have anti-tumor effects [31], and to rescue white blood cells and lymphocytes exposed to ionizing radiation (IR) [21].

In this study, we investigated whether HemoHIM enhances the functions of DCs for potential applications in DC-based anti-tumor therapy. In particular, we investigated the HemoHIM-induced TLR4-mediated functional and phenotypic maturation of bone marrow-derived dendritic cells (BMDCs) and the efficiency of antigenpresentation by these cells to $\mathrm{CD}^{+} \mathrm{T}$ cells and $\mathrm{CD} 8^{+} \mathrm{T}$ cells.

\section{Methods}

\section{Animals and experimental treatments in vivo}

Female 8- to 12-week-old C57BL/6 mice, weighing 20$22 \mathrm{~g}$, were purchased from Orientbio (Orientbio Inc., Iksan, Korea). Female 8- to 12-week-old BALB/c mice, weighing 20-22 g, were purchased from DAE-HAN Biolink (Eumseong, Korea). Male 8- to 12-week-old C57BL/ 6 wild-type, TLR2-deficient, and TLR4-deficient mice were obtained from Dr. Park (College of Medicine,
Konyang University, Daejeon, Korea). The animals were housed in a controlled environment $\left[22 \pm 2{ }^{\circ} \mathrm{C}\right.$ and $50 \pm$ $5 \%$ (relative humidity)] in polycarbonate cages, and fed a standard animal diet with water. For in vivo experiments, mice were randomly divided in to 2 groups of 6 animals. Control group was orally administered with sterilized distilled water (D.W) alone (200 $\mu \mathrm{l} /$ mice) once a day for 4 weeks. And Treatment group was orally administered with HemoHIM (100 mg/kg) in D.W (200 $\mu \mathrm{l} /$ mice) once a day for 4 weeks [21, 32]. All mice were treated in strict accordance with the guidelines issued for the care and use of laboratory animals by the Sunchon National University Institutional Animal Care and Use Committee (SCNU IACUC). All procedures were approved by the SCNU IACUC (Permit Number: 2013-1).

\section{Reagents and antibodies}

Recombinant mouse granulocyte-macrophage colonystimulating factor (GM-CSF) and interleukin (rmIL)-4 were purchased from R\&D Systems (Minneapolis, MN, USA), Dextran-FITC (40,000 Da), propidium iodide (PI), ovalbumin (OVA), and mitomycin C (MMC) were purchased from Sigma-Aldrich (Steinheim, Germany), and carboxyfluorescein succinimidyl ester (CFSE), lipopolysaccharide (LPS), and Pam3CSK4 (Pam3) were purchased from Invitrogen (Carlsbad, CA, USA). The following FITC- or PE- conjugated monoclonal antibodies (Abs) and non-labeled Abs were purchased from BD Biosciences (San Jose, CA, USA) : FITC-annexin V, CD16/32 (2.4G2), CD11c (HL3), CD40 (HM40-3), CD80 (16-10A1), CD86 (GL1), H-2Kb (AF6-88.5), IA[b] (AF6-120.1), and CCR7 (4B12). Cytokine ELISA primary and secondary -antibodies specific for murine IL-1 $\beta$, IL-6, IL-12p70, IFN- $\gamma$, IL-4 and TNF- $\alpha$ were purchased from BD Biosciences (San Jose, CA, USA), and the OT-1 peptide $\left(\mathrm{OVA}_{257-264}\right)$ was purchased from Invivogen (San Diego, CA, USA). $\mathrm{CD}^{+} \mathrm{T}$ cell isolation kit II, CD11c Isolation Kit II and Separation Columns were purchased from MACS Miltenyi Biotec (Auburn, USA). 5-Bromo-2 -Deoxy-Uridine Labeling and Detection Kit III were purchased from Roche (Salt Lake City, UT, USA).

\section{Preparation of HemoHIM}

Equal amounts of the three edible medical herbs [i.e., Angelica Radix (roots of Angelica gigas Nakai), Cnidii Rhizoma (roots of Cnidium offinale Makino), and Paeonia Radix (roots of Paeonia japonica Miyabe)] were mixed at 1:1:1 ratio. To obtain the total extract (HIM-I), this mixture was decocted for $4 \mathrm{~h}$ in boiling water. And then, the total extract (HIM-I) was divided into two parts. The ethanol-insoluble polysaccharide fraction was obtained by from one part of total extract (HIM-I) by 
precipitation in $80 \%(\mathrm{vol} / \mathrm{vol})$ ethanol and then added to the other part of total extract (HIM-I), freeze-dried, and stored at $-20{ }^{\circ} \mathrm{C}$ (HemoHIM). HemoHIM was composed of carbohydrates (60.4\%), protein (6.0\%), and other components $(33.6 \%)$ and other including polyphenols (33.6\%), (data not shown). The immune modulating components in HemoHIM were the ethanol-insoluble fraction, the polysaccharide content was $40.9 \% \pm 3.8$ (data not shown) and other carbohydrate components in HemoHIM were acidic-polysaccharide ethanol soluble fraction, the polysaccharide content of which was $19.5 \%$ (data not shown). In addition, the functional component analysis in the ethanol-soluble fraction of HemoHIM was performed via high-performance liquid chromatography (HPLC) using phytochemicals, as follows: gallic acid $[0.2 \%( \pm 0.06)]$, chlorogenic acid $[0.33 \%( \pm 0.05)]$, paeoniflorin $[1.32 \%( \pm 0.15)]$, nodakenin $[0.58 \%$ $( \pm 0.04)]$, and benzoic acid $[0.17 \%( \pm 0.05)]$. In particular, these herbs are suggested as raw materials in the Korean Food Code. Finally, HemoHIM has been proven to be safe for long-term administration [21, 24-26, 29-34].

\section{Generation and activation of bone marrow-derived DCs}

BMDCs were obtained from the femurs and tibias of C57BL/6 mice, and red cells were treated with lysis buffer solution (4.15 g of ammonium chloride per $500 \mathrm{~mL}$ of $0.01 \mathrm{M}$ Tris- $\mathrm{HCl}$ buffer). The cells were washed and cultured in six-well tissue culture plates at $1 \times 10^{6}$ cells/ $\mathrm{mL}$ in complete RPMI culture medium supplemented with $10 \%$ fetal bovine serum (FBS), 2-mecaptoethanol (50 $\mu \mathrm{M} / \mathrm{mL})$, IL-4 (1,000 U/mL), and GM-CSF (1,000 U/ $\mathrm{mL})$. The culture medium was changed on culture days 2 and 4. New medium and cytokines (i.e., GM-CSF and IL-4) were added after flushing out non-adherent cells. On day 6, loosely adherent clustered cells were defined as immature BMDCs, treated with LPS and HemoHIM for $24 \mathrm{~h}$ and then harvested.

\section{Isolation and activation of spleen-DCs}

Mice were orally administered daily for 4 weeks. After 4 weeks, spleen-DCs (s-DCs) from splenocytes suspensions of $\mathrm{C} 57 \mathrm{BL} / 6$ mice were isolated using the $\mathrm{CD} 11 / \mathrm{c}^{+}$ isolation kit II and Separation Columns according to the manufacturer s instruction. Purity was greater than $94 \%$. S-DCs and treated with lipopolysaccharide (LPS, $100 \mathrm{ng} /$ $\mathrm{ml}$ ). After $24 \mathrm{~h}$ incubation, we analyzed co-stimulatory of s-DCs using the flow cytometory, and measured cytokine production with ELISA assay [35-43].

\section{Cytotoxicity assay}

Apoptosis induction by HemoHIM was quantified via flow cytometry using Annexin V-FITC and a propidium iodide (PI) solution, according to the manufacturer s instructions. Briefly, BMDCs $\left(1 \times 10^{6} /\right.$ well $)$ were seeded onto 24-well plates and exposed to HemoHIM or LPS for $24 \mathrm{~h}$. Apoptosis was quantified by staining with Annexin V-FITC/PI. Finally, the samples were analyzed by flow cytometry, and apoptosis percentages were calculated by counting Annexin V-positive cells.

\section{Flow cytometry}

After incubation for $24 \mathrm{~h}$, DCs were harvested, washed with fluorescence-activated cell sorting (FACS) solution buffer, and blocked with anti-mouse CD16/32, which blocks Fc $\gamma$ II and FcyIII receptors on DCs, for $30 \mathrm{~min}$ on ice. After blocking, the cells were stained with fluorescence-labeled antibodies (i.e., anti-mouse CD11c-FITC, CD40-PE, CD80PE, CD86-PE, MHC I-PE, or MHC II-PE) for $30 \mathrm{~min}$ on ice, washed with FACS solution buffer, and analyzed via flow cytometry. Data analysis was performed using the $\mathrm{BD}$ FACS Diva software.

\section{Antigen uptake assay}

To assess the antigen uptake activity of BMDCs, on culture day 6, the BMDCs were treated with HemoHIM $(100 \mu \mathrm{g} / \mathrm{ml})$ and LPS $(1 \mu \mathrm{g} / \mathrm{ml})$ or left untreated for $24 \mathrm{~h}$. Then, $2 \times 10^{5}$ of the obtained mature-BMDCs were incubated at $37^{\circ} \mathrm{C}$ for $2 \mathrm{~h}$ with $1 \mathrm{mg} / \mathrm{mL}$ FITC-dextran, washed with FACS solution buffer, and analyzed via flow cytometry.

\section{OVA-specific Th1 cell preparation}

The mice were immunized intraperitoneal injection (i.p.) with incomplete Freunds adjuvant (IFA) or complete Freunds adjuvant (CFA) (Pierce) and immunized with OVA on day 0 (OVA-IFA) and on day 7 (OVA-CFA). Spleens were harvested from OVA-immunized mice on day 14 . $\mathrm{CD}^{+} \mathrm{T}$ cells were isolated from the spleens using a $\mathrm{CD} 4^{+} \mathrm{T}$ cell Isolation Kit II and then activated with OVA $(100 \mu \mathrm{g} / \mathrm{ml})$ and syngeneic APCs. OVAspecific $\mathrm{CD}^{+}{ }^{+} \mathrm{T}$ cells were selected by limiting dilution, and OVA-specific T $\left(\mathrm{CD} 4^{+}, \mathrm{IFN}-\gamma^{+}\right)$cells were counted using a FACScanto II $[10,44,45]$.

\section{Proliferation assay of OVA-specific Th1 cells}

To investigate the antigen-presenting ability of OVA or OVA-pulsed HemoHIM BMDCs, $3 \times 10^{4}$ cells were incubated with $5 \times 10^{4}$ OVA-specific Th1 cells for $24 \mathrm{~h}$ or $48 \mathrm{~h}$ in $200 \mu \mathrm{l}$ of culture medium in 96-well cell culture plates. Also, to investigate the antigen-presenting ability of OVA-pulsed s-DCs of group with oral administered HemoHIM, $3 \times 10^{4}$ s-DCs of orally administered group (D.W or HemoHIM) were incubated with $5 \times 10^{4}$ OVAspecific Th1 cells for $24 \mathrm{~h}$ or $48 \mathrm{~h}$ in $200 \mu \mathrm{l}$ of culture medium in 96-well cell culture plates. Proliferation was evaluated using a 5-bromo-2 -deoxy-uridine Labeling and Detection Kit III. Cytokine levels were determined 
via ELISA. The results are expressed as the mean of experiments performed in triplicate.

\section{Mixed-lymphocyte reaction (MLR) assay}

$\mathrm{CD}^{+}{ }^{+} \mathrm{T}$ cells from splenocyte suspensions from BALB/c mice were isolated using a $\mathrm{CD} 4^{+} \mathrm{T}$ cell isolation kit II, and the purity was greater than $95 \%$. On culture day 6, BMDCs were incubated with or without HemoHIM and LPS for $24 \mathrm{~h}$. Mature BMDCs were harvested, treated with $50 \mu \mathrm{g} / \mathrm{ml}$ of MMC for $25 \mathrm{~min}$, and then washed. OVA 257 $264^{- \text {specific }} \mathrm{CD}^{+} \mathrm{T}$ cells were obtained from splenocyte suspensions from C57BL/6 OT-1 T-cell receptor (TCR) transgenic mice. $\mathrm{CD}^{+} \mathrm{T}$ cells were co-cultured with BMDCs, and $\mathrm{CD}_{4}^{+} \mathrm{T}$ cell proliferation was determined using a 5-bromo-2 -deoxy-uridine Labeling and Detection Kit III. In addition, cytokine secretion by $\mathrm{CD} 4^{+} \mathrm{T}$ cells was determined using an ELISA. The results are expressed as the mean of triplicate experiments. $\mathrm{OVA}_{257-264}$-specific $\mathrm{CD}^{+} \mathrm{T}$ cells were washed with PBS, labeled with $1 \mu \mathrm{M}$ CFSE in PBS, co-cultured with BMDCs in 96-well Ubottom plates for 2 days, harvested, and washed with PBS. Proliferation was then evaluated via flow cytometry. $\mathrm{OVA}_{257-264}$-specific $\mathrm{CD}^{+} \mathrm{T}$ cells were co-cultured with BMDCs for 1 day, and cytokine secretion and intracellular cytokine concentrations were determined by ELISA and flow cytometry.

\section{Cytokine assay}

Culture supernatants were analyzed by enzyme-linked immunosorbent assay (ELISA). The levels of various cytokines secreted by BMDCs, allogeneic $\mathrm{CD}^{+} \mathrm{T}$ cells, OVA-specific Th1 cells, and $\mathrm{CD}^{+} \mathrm{T}$ cells were measured by ELISA.

\section{Intracellular staining}

$\mathrm{CD}^{+} \mathrm{T}$ cells were stained with biotin-anti-CD8 in the presence of anti-FcR (2.4G2), fixed with $4 \%$ paraformaldehyde in PBS, permeabilized with $0.1 \%$ saponin, and stained with FITC-anti-IFN- $\gamma$ and PE-anti-CD8. CD8 ${ }^{+} \mathrm{T}$ cells were then gated and analyzed using a FACScanto II (BD Biosciences).

\section{Statistical analysis}

The differences between groups are presented as the mean \pm S.D. of three replicate experiments. The significance of differences was determined using the Student $\mathrm{s}$ t-test. Probability values of $<0.05$ were considered significant ( $\mathrm{P}$ values are indicated as follows: ${ }^{*}<0.05,{ }^{* *}<0.01,{ }^{* m *}<0.001$, or ${ }^{+}<$ $\left.0.05,{ }^{++}<0.01,{ }^{+++}<0.001\right)$.

\section{Results}

HemoHIM is not cytotoxic to BMDCs

We investigated whether HemoHIM at different concentrations induces apoptosis in BMDCs. As shown in Fig. 1, HemoHIM did not induce BMDC apoptosis at any of the examined concentrations.

\section{HemoHIM induces the maturation of bone marrow- derived DCs}

Flow cytometry was used to assess the expression of BMDC maturation markers, including CD40, CD80, CD86, and MHC I and II. In this experiment, BMDCs treated with LPS were used as a positive control. As shown in Fig. 2a, untreated BMDCs expressed CD40 (6.7 \%), CD80 (58.1\%), CD86 (57.9\%), MHC I (31.2\%), and MHC II (64.8\%), where the listed percentages are indicate the percentage of cells expressing these markers.

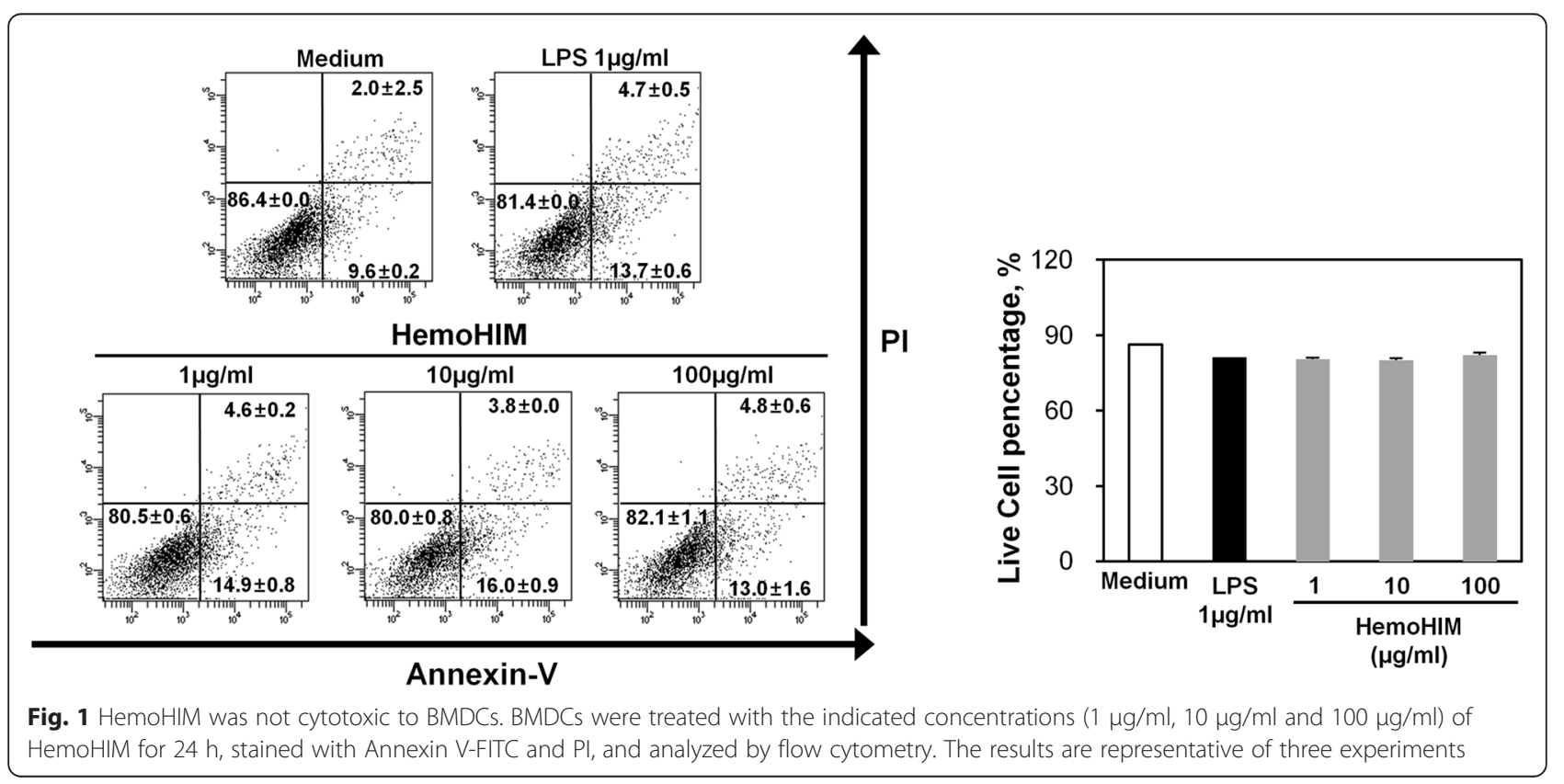







Compared to untreated BMDCs, BMDCs treated with LPS expressed higher levels of surface maturation markers: CD40 (75.1 \%), CD80 (87.9 \%), CD86 (80.3 \%), MHC I (74.7 \%), and MHC II (90.0 \%). In addition, BMDCs treated with HemoHIM at concentrations of $1 \mu \mathrm{g} / \mathrm{ml}, 10 \mu \mathrm{g} / \mathrm{ml}$ and $100 \mu \mathrm{g} / \mathrm{ml}$ exhibited increased expression of surface markers. In particular, BMDCs treated with HemoHIM $(100 \mu \mathrm{g} / \mathrm{ml})$ expressed significantly higher levels of co-stimulatory molecules: CD40 (80.2 \%), CD80 (73.1 \%), CD86 (73.8 \%), MHC I
(52.9 \%), and MHC II (85.2 \%). These surface markers of BMDC maturation activate $\mathrm{T}$ cell responses via cellto-cell interactions. However, this phenomenon requires interactions between surface markers and cytokines [1-10]. During maturation, BMDCs expressed higher levels of various co-stimulatory molecules and cytokines [1-10]. Cytokines, such as, IL-1ß, IL-6, IL$12 \mathrm{p} 70$, and TNF- $\alpha$, are important markers of BMDC maturation [1-10]. In particular, IL-12p70 is an important marker of DC maturation and stimulates Th1 cells
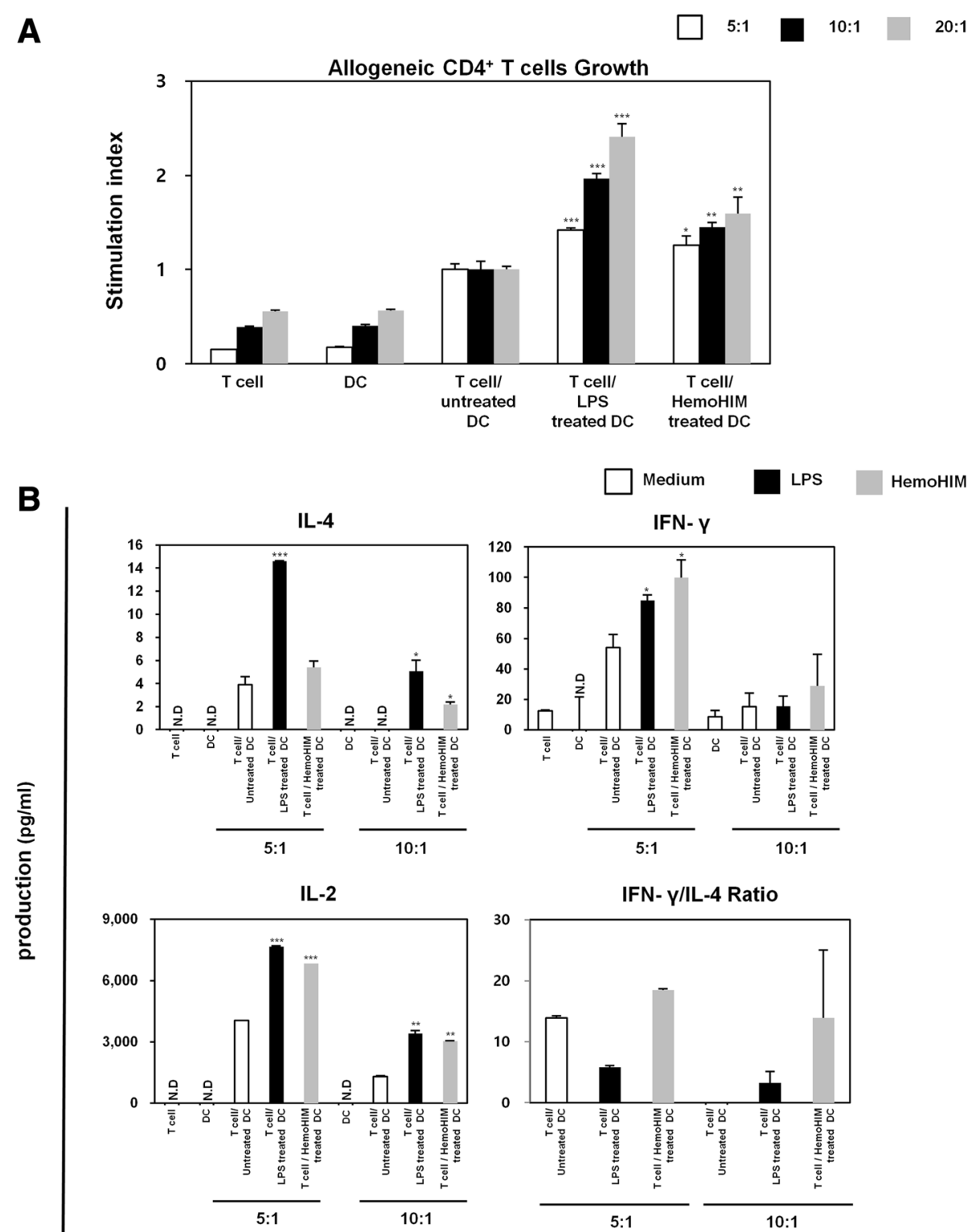

Fig. 3 HemoHIM-treated BMDCs induced the activations of allogeneic CD4 ${ }^{+} T$ cells derived from BALB/C mice. a CD4 ${ }^{+} T$ cells were co-cultured for $48 \mathrm{~h}$ with C57BL/6-derived BMDCs that were treated with LPS $(1 \mathrm{~g} / \mathrm{ml})$ or HemoHIM $(100 \mathrm{~g} / \mathrm{ml})$. The proliferation of allogeneic CD4 ${ }^{+}$T cells was assessed using a Bromo-kit. b Culture supernatants were harvested after $48 \mathrm{~h}$, and cytokine levels were measured by ELISA. The results are representative of three experiments. ${ }^{*}, p<0.05,{ }^{* *}, p<0.01$, and ${ }^{* * *}, p<0.001$ vs. CD4 ${ }^{+} T$ cells co-cultured with untreated BMDCs. Not detection (N.D) showed less than $10 \mathrm{pg} / \mathrm{ml}$ of cytokine secretion in this experiment 
[1-10]. In this experiment, BMDCs treated with LPS were used as a positive control. The secretion of IL12 p70 by BMDCs treated with a high concentration of HemoHIM $(100 \mu \mathrm{g} / \mathrm{ml})$ was higher than that of untreated BMDCs (Fig. 2b). The secretion of IL-1 $\beta$, IL-6, and TNF- $\alpha$ by BMDCs exhibited similar patterns. Immature DCs have high antigen-uptake abilities, but after maturation, the cells lose this ability and mature into APCs [1-10]. Therefore, we examined whether mature DCs exhibited reduced antigen-uptake activity. BMDCs cultured in the presence or absence of HemoHIM or LPS were incubated with FITC-dextran for $24 \mathrm{~h}$, and FITC-dextran-positive cells were then analyzed by flow cytometry. We found that the antigen uptake activity of HemoHIM-treated BMDCs was significantly lower than that of untreated BMDCs [(Fig. 2c) untreated: $30.3 \% \pm 0.6$, HemoHIM: $17.4 \%$ $\pm 1.4)]$. Parallel experiments were performed at $4{ }^{\circ} \mathrm{C}$ to examine the non-specific uptake of FITC-dextran by BMDCs. At $4{ }^{\circ} \mathrm{C}$, FITC-dextran was internalized by fewer than $5 \%$ of DCs. Furthermore, HemoHIMtreated mature DCs exhibited a lower antigen uptake capacity for FITC-dextran than immature DCs, indicating that HemoHIM was more functionally active in mature DCs. These finding suggest that HemoHIM enhances the phenotypic and functional maturation of BMDCs.

\section{HemoHIM-treated bone marrow-derived DCs enhance allogeneic $\mathrm{CD}^{+} \mathrm{T}$ cell proliferation}

To examine the ability of HemoHIM-treated BMDCs to increase $\mathrm{CD}^{+}$and $\mathrm{CD} 8^{+} \mathrm{T}$ cell responses, we performed an allogeneic MLR assay using BALB/c $\mathrm{CD} 4^{+} \mathrm{T}$ cells. $\mathrm{CD}^{+}{ }^{+} \mathrm{T}$ cells were co-cultured with untreated BMDCs, LPS-treated BMDCs, or HemoHIM-treated BMDCs. After co-culture for 2 days, $\mathrm{CD} 4^{+} \mathrm{T}$ cells co-cultured with HemoHIM-treated BMDCs were found to induce more $\mathrm{CD}_{4}^{+} \mathrm{T}$ cell proliferation than $\mathrm{CD} 4^{+} \mathrm{T}$ cells cocultured with untreated BMDCs (Fig. 3a). To determine whether HemoHIM-treated BMDCs modulate cytokine secretion during allogeneic $\mathrm{T}$ cell responses, we measured IL-2, IFN- $\gamma$, and IL-4 levels in supernatants after co-culture for 2 days. HemoHIM-treated BMDCs cocultured with $\mathrm{CD} 4^{+} \mathrm{T}$ cells secreted higher levels of IFN- $\gamma$, IL-4, and IL-2 than untreated BMDCs (Fig. 3b). In addition, the proliferation and cytokine secretion of

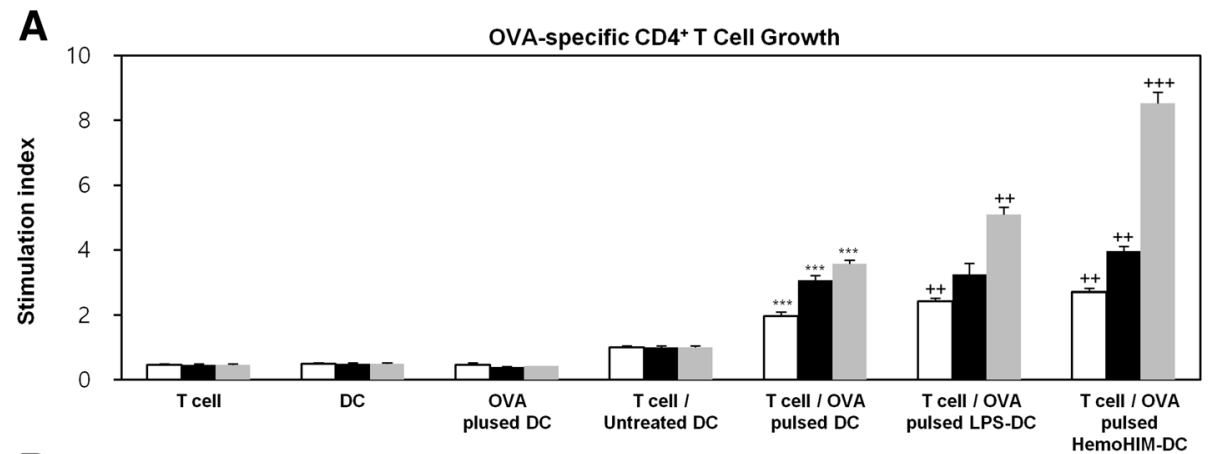

B

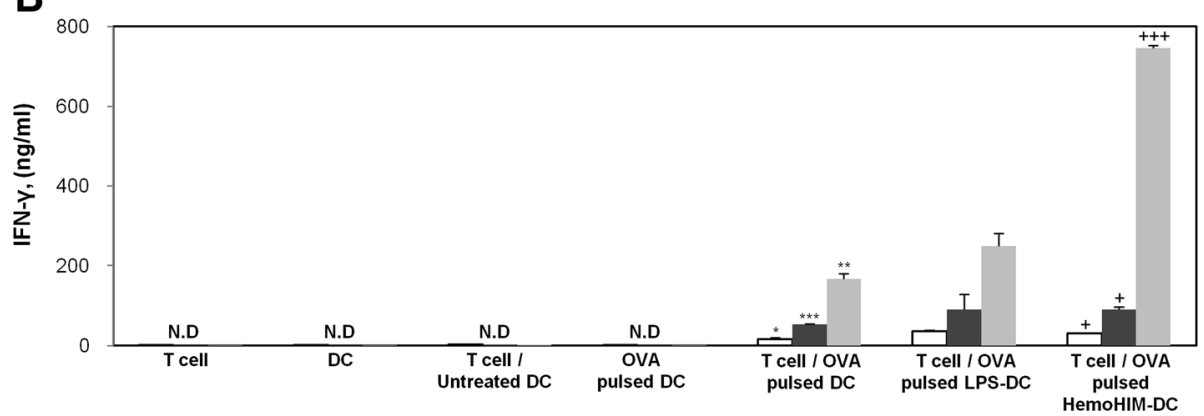

Fig. 4 HemoHIM-treated BMDCs induced the activation of antigen-specific Th1 cells. a OVA-specific Th1 cells were co-cultured for $48 \mathrm{~h}$ with C57BL/6-derived BMDCs that were treated with LPS (1 $\mathrm{g} / \mathrm{ml})$ or HemoHIM (100 $\mathrm{g} / \mathrm{ml})$. The proliferation of OVA-specific Th1 cells was then assessed using a Bromo-kit. b Culture supernatants were harvested after $24 \mathrm{~h}$, and cytokine levels were measured by ELISA. The results are representative of three experiments. ${ }^{*}, p<0.05,{ }^{* *}, p<0.01$, and ${ }^{* * *}, p<0.001$ vs. OVA-specific T cells co-cultured with untreated BMDCs. ${ }^{+}, p<0.05,{ }^{++}, p<0.01$, and ${ }^{+++}, p<0.001$ vs. OVA-specific T cells co-cultured with OVA-pulsed BMDCs. Not detection (N.D) showed less than $10 \mathrm{pg} / \mathrm{ml}$ of cytokine secretion in this experiment 
$\mathrm{CD}^{+} \mathrm{T}$ cells increased in accordance with the $\mathrm{T}$ cell to $\mathrm{DC}$ ratio, and IFN- $\gamma$ production increased more than IL-4 production (Fig. $3 \mathrm{~b}$ ). These results suggest that the activation and maturation of BMDCs by HemoHIM activates T cells and enhances Th1 responses.

\section{HemoHIM-treated bone marrow-derived DCs enhance antigen-specific $\mathrm{CD}^{+}{ }^{+}$Th1 cell activation}

Next, we investigated whether HemoHIM treated BMDCs enhance antigen-specific $\mathrm{CD} 4^{+}$Th1 cell responses using OVA-specific Th1 cells. To measure the proliferation and cytokine secretion of OVA-specific Th1 cells, we cocultured OVA-specific Th1 cells with or without treated BMDCs (LPS or HemoHIM). OVA-specific Th1 cells cocultured with HemoHIM-treated BMDCs proliferated more than cells co-cultured with untreated BMDCs (Fig. 4a). Furthermore, OVA-specific Th1 cells co-cultured with HemoHIM-treated BMDCs secreted significantly more IFN- $\gamma$ than cells co-cultured with untreated BMDCs (Fig. 4b), indicating that HemoHIM enhances antigenspecific Th1 cell responses induced by activated DCs.

\section{HemoHIM-treated bone marrow-derived DCs enhance OT-} $1 \mathrm{CD}^{+} \mathrm{T}$ cell activation

The presentation of captured antigens to cytotoxic $\mathrm{CD}^{+} \mathrm{T}$ cells is important for the induction of anti-tumor immunity.
To examine the ability of HemoHIM-treated BMDCs to increase antigen-presentation to $\mathrm{CD}^{+} \mathrm{T}$ cells, we used OT-1 mice. CFSE-labeled $\mathrm{CD}^{+}{ }^{+}$T cells were co-cultured with untreated BMDCs pulsed with $\mathrm{OVA}_{257-264}$ or treated BMDCs (LPS or HemoHIM) pulsed with $\mathrm{OVA}_{257-264} \mathrm{CD}^{+} \mathrm{T}$ cells co-cultured with HemoHIM-treated BMDCs proliferated more than $\mathrm{CD}^{+} \mathrm{T}$ cells co-cultured with untreated BMDCs (Fig. 5). Furthermore, $\mathrm{CD}^{+} \mathrm{T}$ cells co-cultured with HemoHIM-treated BMDCs produced significantly more IFN- $\gamma$ than those co-cultured with untreated BMDCs, presumably due to the secretion of intracellular cytokines (Fig. 6a) and the production (Fig. 6b) of cytokines. These results supported the notion that HemoHIM enhances $\mathrm{CD}^{+} \mathrm{T}$ cell responses by activating DCs.

\section{HemoHIM induces TLR4-mediated BMDC maturation}

Associations between activated DCs and TLRs are critical for the tailoring of immune responses. We investigated whether TLRs on BMDCs recognized HemoHIM using $\mathrm{TLR}^{-/-}$and TLR4 ${ }^{-/-}$mice. To confirm that TLRs on BMDCs interact with HemoHIM, wild-type, TLR2 ${ }^{-/-}$, or $\mathrm{TLR}^{-1-}$ BMDCs were stimulated with HemoHIM for 24 h. Pam3 (a TLR2 agonist) and LPS (a TLR4 agonist) were used as positive controls. After stimulation for $24 \mathrm{~h}$, we measured the expressions of the BMDCs maturation markers CD40, CD80, CD86, and MHC II and

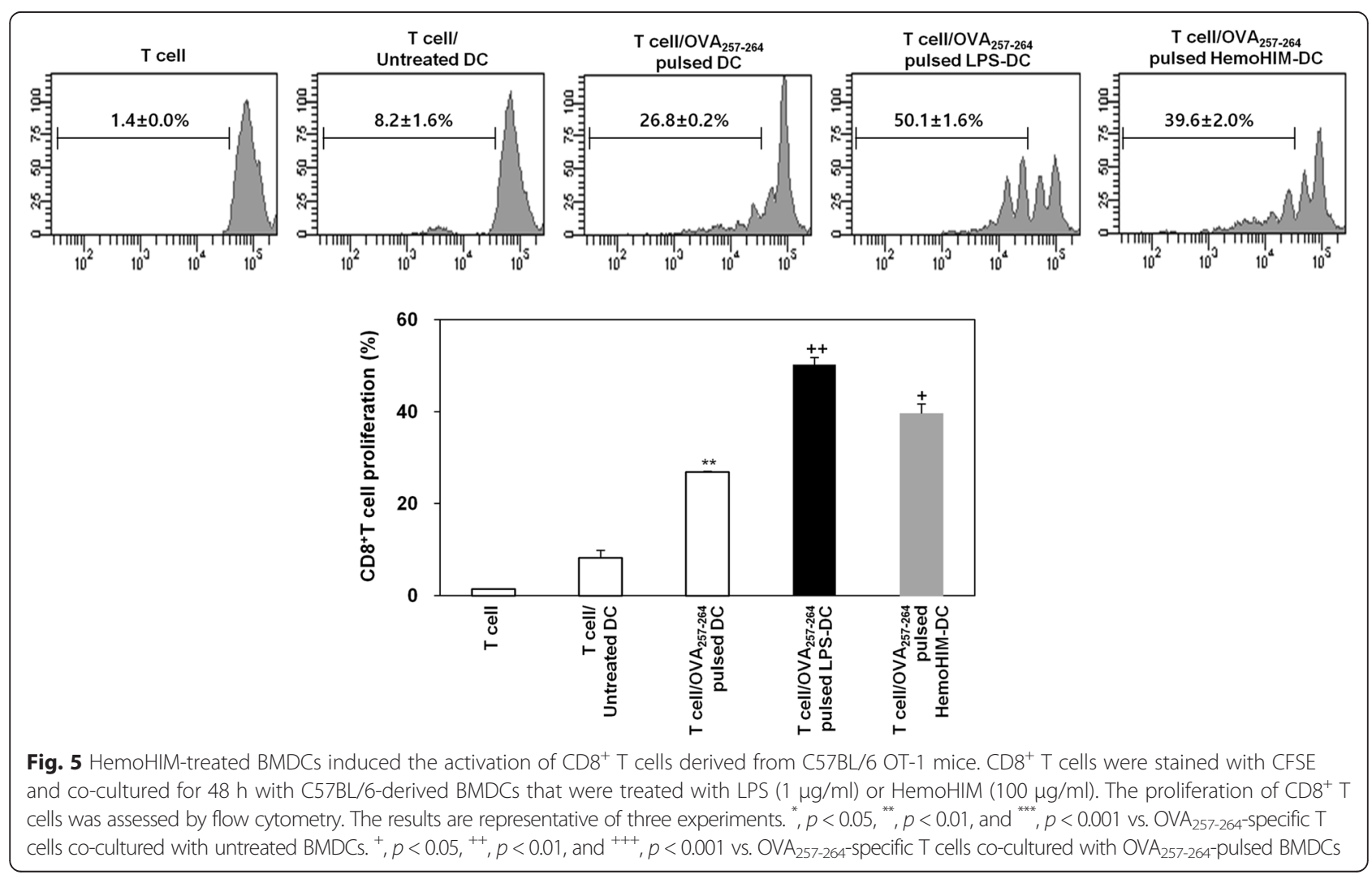




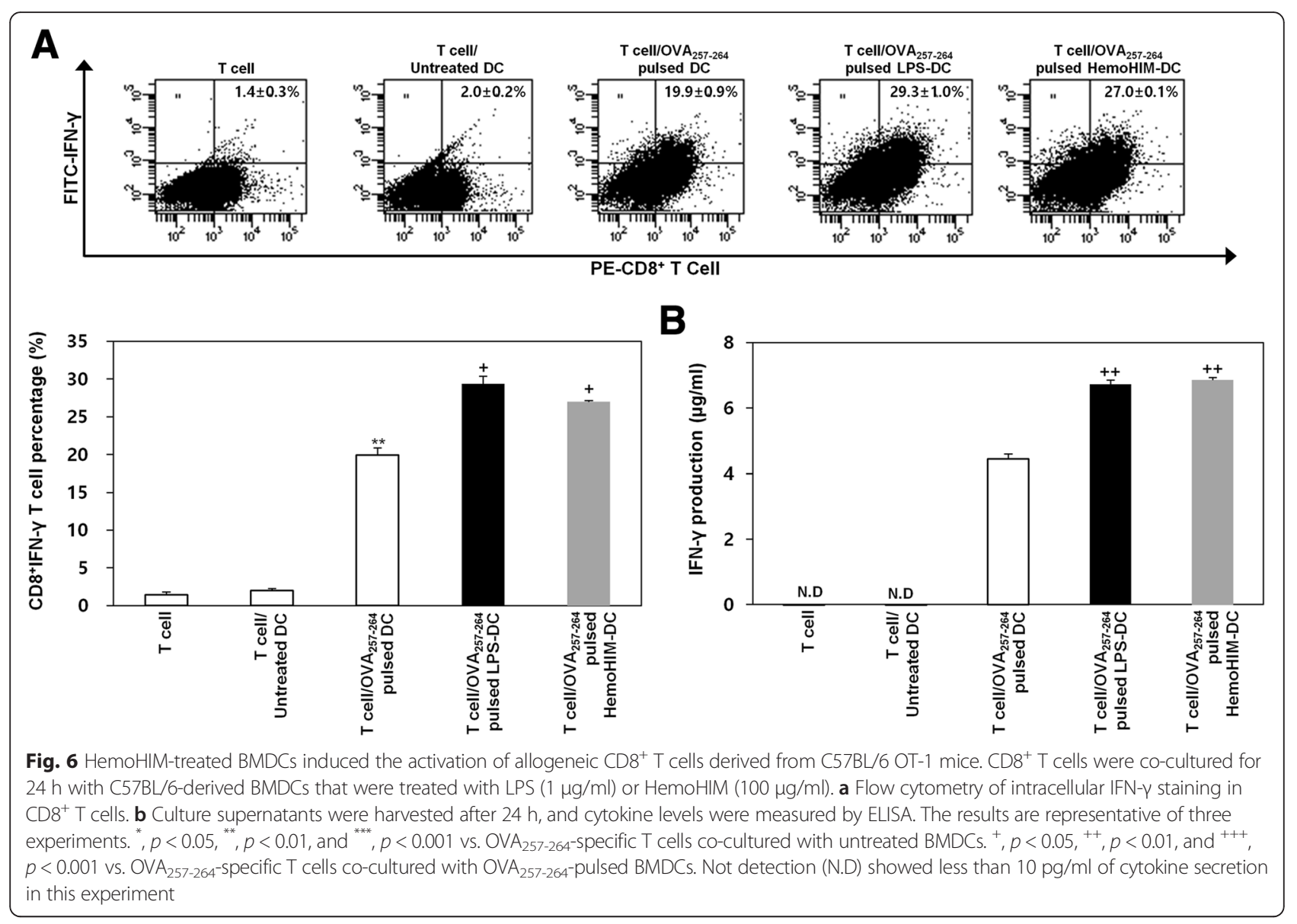

of various cytokines (i.e., IL-1 $\beta$, IL- 6 , and TNF- $\alpha$ ). As shown in Fig. 7a, untreated BMDCs from wild-type, $\mathrm{TLR}^{2 /-}$, and $\mathrm{TLR} 4^{-/-}$mice expressed similar levels of these markers and cytokines. However, HemoHIM-treated BMDCs from wild-type and TLR $2^{-1-}$ mice exhibited higher expression of the investigated surface maturation markers than untreated wild-type or TLR2 ${ }^{-/-}$BMDCs [wild-type: CD40 (24.4 \%), CD80 (75.5 \%), CD86 (76.1 \%), and MHC II (75.7 \%); and TLR2 ${ }^{-/-}$: CD40 (28.5\%), CD80 (78.3\%), CD86 (74.6\%), and MHC II (67.6\%)]. In contrast, these effects were diminished in BMDCs from TLR $4^{-/}$mice, indicating that HemoHIM is an agonist of TLR4 in BMDCs [TLR4 $^{-1-}$ : CD40 (14.4\%) and CD80 (67.9\%)]. In contrast, the expression levels of CD80 and CD86 were significantly more reduced by HemoHIM in BMDCs from $\mathrm{TLR}^{-/-}$ mice than in BMDCs from wild-type or $\mathrm{TLR}^{-/-}$mice [wild-type: CD80 (75.5 \%) and CD86 (76.1\%); $\mathrm{TLR}^{-/-}$: CD80 (78.3\%) and CD86 (74.6\%); and TLR4 ${ }^{-1-}$ : CD80 (67.9 \%) and CD86 (67.8\%)]. In addition, cytokine production exhibited a pattern similar to that observed for surface molecules (Fig. 7b). These results demonstrate that HemoHIM induces TLR4-mediated BMDC maturation.

\section{HemoHIM enhances DCs maturation in vivo}

Through the results of the previous, we demonstrated that HemoHIM enhances the phenotypic and functional maturation of BMDCs and matured BMDCs by HemoHIM enhances antigen-specific $\mathrm{T}$ cell responses through in vitro. Likewise, we investigated whether HemoHIM enhanced function of s-DCs in vivo by oral administration HemoHIM. Mice were orally administered for 4 weeks. After 4 weeks, we isolated s-DCs in the spleen of mice each groups. After isolation, s-DCs were stimulated with LPS $(100 \mathrm{ng} / \mathrm{ml})$ for $24 \mathrm{~h}$ in order to maturation degree of s-DCs by LPS. After $24 \mathrm{~h}$, we measured the expression of DC maturation markers such as CD40, CD80, CD86, MHC I, and MHC II and secretion cytokine IL-12p70. In the two groups, the results that s-DCs in the group with oral administration HemoHIM higher increased degree of maturation by LPS than s-DCs in the group with oral administration D.W through CD40 and CD80 among maturation markers. Also IL-12p70 secretion by s-DCs treated LPS was increased by administration HemoHIM group than by administration D.W group (Fig. 8a, b). Next we experimented that matured s-DCs of group with oral administered HemoHIM 


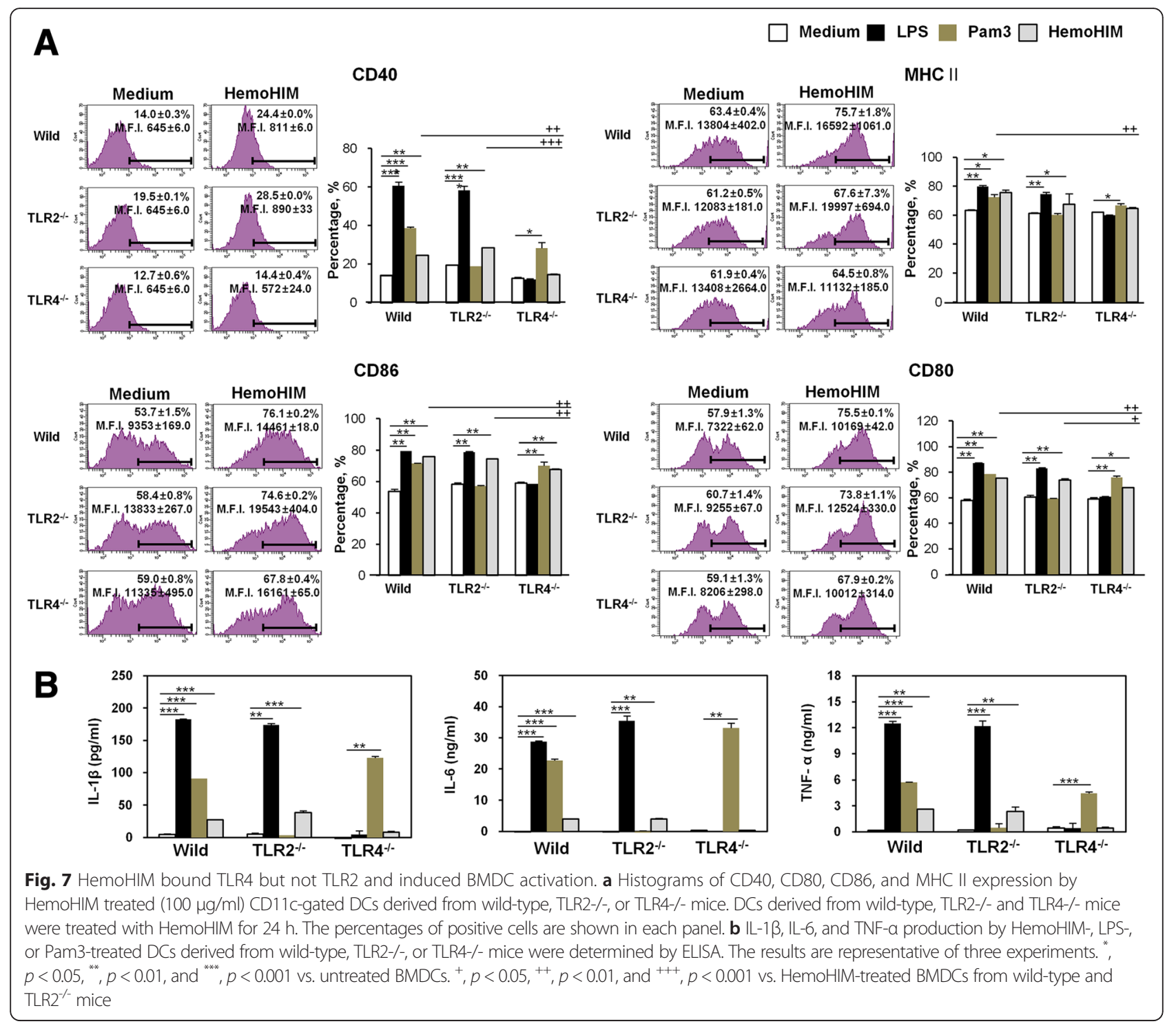

enhance antigen-specific $\mathrm{T}$ cell response with OVAspecific $\mathrm{T}$ cells than group with oral administered D.W. Proliferation and cytokine secretion of OVA specific $\mathrm{T}$ cell co-cultured OVA-pulsed s-DCs significantly increase by administration HemoHIM group than by administration D.W group. This result (Fig. 9) that HemoHIM enhanced functional maturation of s-DCs by in vivo.

\section{Discussion}

Diseases are caused by the failure to induce appropriate immune responses to invading pathogens or tumor cells. Tumors are well-known sources of biological substances and release immunosuppressive factors to evade the host immune surveillance system [2, 46-48]. During neoplastic disease development, the bodys natural defenses are typically attenuated [49-51]. In particular, DCs that have infiltrated tumor tissues are known to exhibit reduced expressions of surface molecules and to produce fewer cytokines; this finding implies that tumor-derived factors impede DC maturation [49-51]. Furthermore, these effects appear to be maturation-dependent and to act on DC precursors rather than on mature DCs [2]. Recent studies indicate that DCs are the most potent immune cell vaccine candidate and that mature DCs are likely the best cell type for clinical use [2]. Immature DCs capture antigens generated by pathogens and tumors and then enter a maturation cascade. The resulting mature DCs exhibit elevated expression of co-stimulatory molecules and secrete more cytokines to promote immune synapse formation, antigen processing, antigen presentation to T cells, and T cell activation [10]. Therefore, DCs could potentially be used in vaccines for tumorimmunotherapy and to treat other diseases $[52,53]$. In this study, we focused on the enhancement of DC activity. As 
A

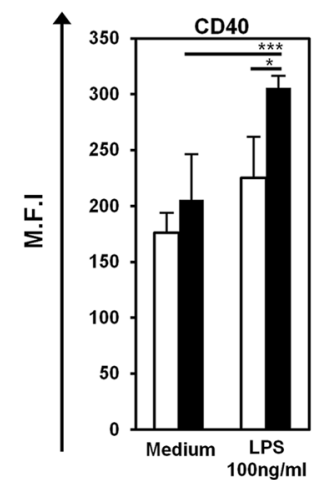

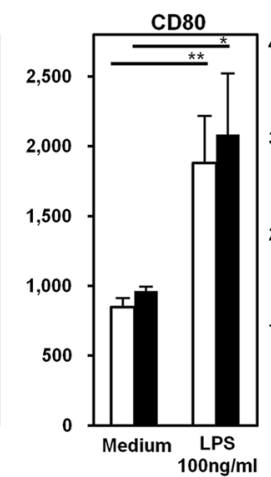
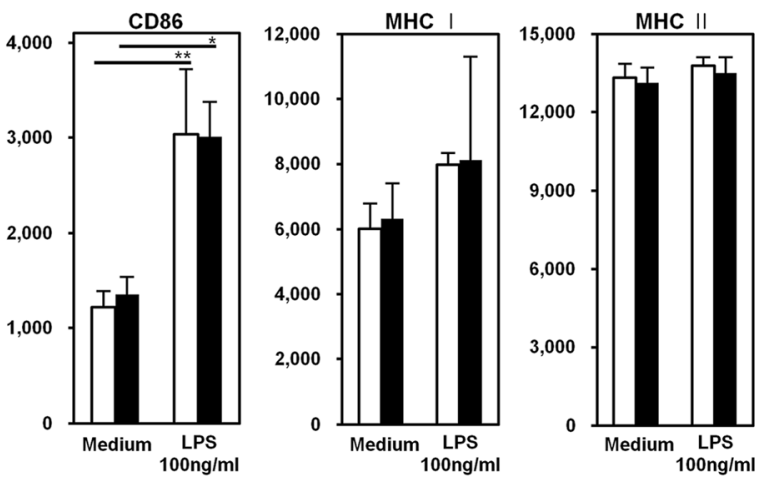

B

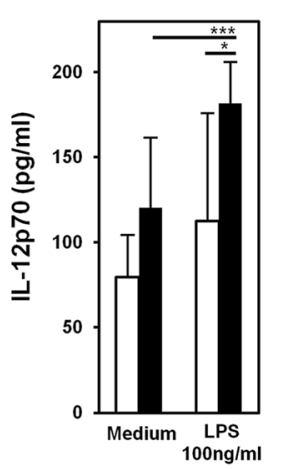

Fig. 8 HemoHIM induced the phenotypic maturation and cytokine secretion of DCs in vivo. S-DCs was treated with the indicated concentrations of LPS for $24 \mathrm{~h}$. a Flow cytometry was used to analyze the expressions of co-stimulatory molecules on CD11 $\mathrm{c}^{+}$-gated s-DCs. Mean fluorescence intensities (M.F.I) of positive cells are shown for each panel. b IL-12p70 levels in HemoHIM-oral administration mice s-DCs were analyzed by ELISA. Results are representative of three experiments. ${ }^{*}, p<0.05,{ }^{* *}, p<0.01$, and ${ }^{* * *}, p<0.001$ vs. untreated BMDCs. ${ }^{+}, p<0.05,{ }^{++}, p<0.01$, and $^{+++}$, $p<0.001$ vs. LPS treated DCs of control group

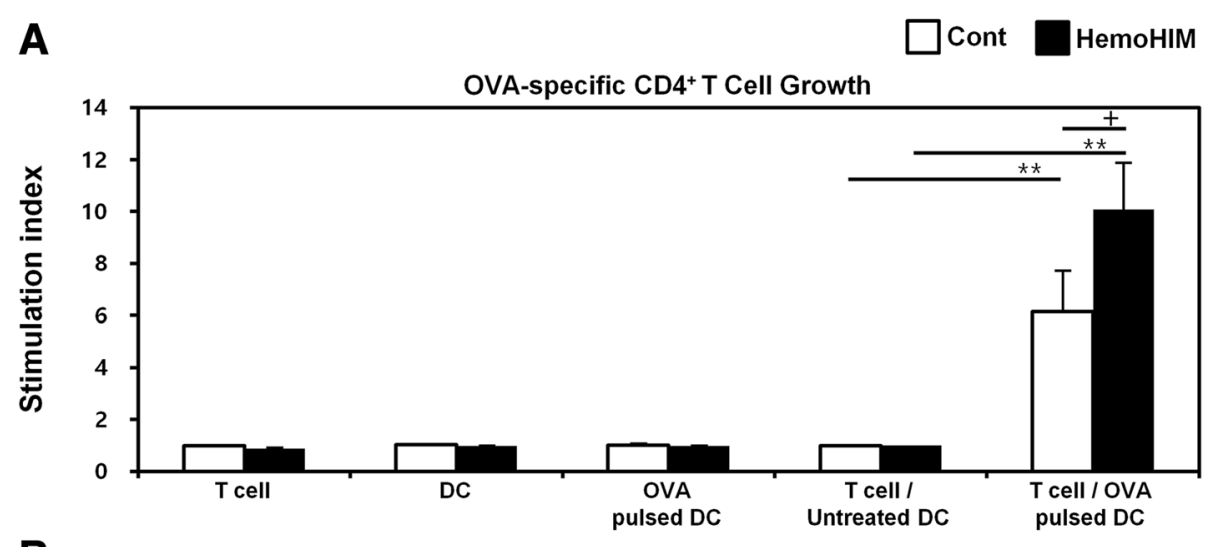

B

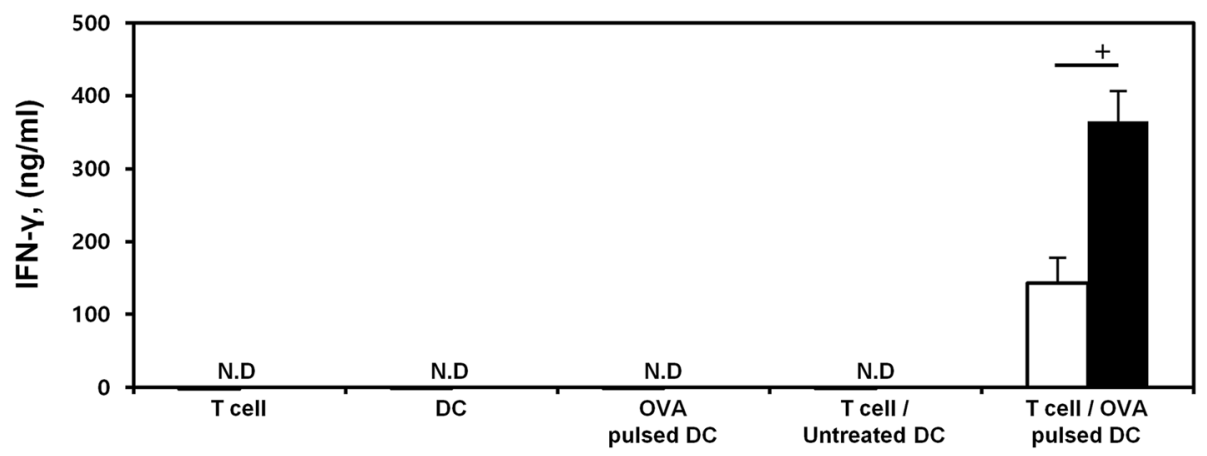

Fig. $9 \mathrm{~S}$-DCs of HemoHIM-oral administration mice induced the activation of antigen-specific $T$ cells. OVA-specific $T$ cells co-cultured for $48 \mathrm{~h}$ with $\mathrm{s}$-DCs of each group pulsed with OVA (100 $\mathrm{g} / \mathrm{ml})$. a The proliferation of OVA-specific T cells was assessed by flow cytometry. b Culture supernatants were harvested after $24 \mathrm{~h}$, and IFN- levels were measured by ELISA. Results are representative of three experiments. ${ }^{+}, p<0.05,{ }^{++}, p<0.01$, and ${ }^{+++}, p<0.001$ vs. OVA-specific T cells co-cultured with untreated s-DC. ${ }^{*}, p<0.05,{ }^{* *}, p<0.01$, and ${ }^{* * *}, p<0.001$ vs. OVA-specific T cells co-cultured with OVA-pulsed DCs of control group. Not detection (N.D) showed less than $10 \mathrm{pg} / \mathrm{ml}$ of cytokine secretion in this experiment 
mentioned above, HemoHIM has several biological activities and is non-cytotoxic, but it remained unknown whether HemoHIM modulates T cell responses in a DCmediated manner. The present study demonstrates that HemoHIM interacts with BMDCs and induces DC maturation and that these events result in up-regulated expression of co-stimulatory molecules and the loss of the ability to take up antigens. Furthermore, HemoHIM-treated BMDCs were found to secrete considerably more cytokines (i.e., IL-1 $\beta$, IL-6, IL-12p70, and TNF- $\alpha$ ) than untreated cells. Of the cytokines secreted by DCs, IL12 p70 is most important in the context of DC maturation because this ctokine induces the differentiation of naive $\mathrm{CD}^{+} \mathrm{T}$ cells into Th1 cells $[9,10]$. In the present study, HemoHIM was found to induce the phenotypic and functional maturation of DCs, indicating that this treatment has immunoadjuvant potential, as suggested previously [1-10]. After maturation, DCs interact with T cells using co-stimulatory molecules and cytokines. The present study demonstrates that DCs that mature in response to HemoHIM induce greater proliferation and cytokine secretion by allogeneic $\mathrm{CD} 4^{+} \mathrm{T}$ cells and OVA-specific Th 1 cells than their untreated counterparts. In particular, IFN$\gamma$ secretion was more enhanced than IL-4 secretion. It is also possible HemoHIM induces Th1 response because IL-12p70 is associated with Th1 activation. In addition, in the present study, HemoHIM-treated BMDCs enhanced $\mathrm{CD}^{+}{ }^{+} \mathrm{T}$ cell responses in OT- 1 mice. These results demonstrated that HemoHIM-treated BMDCs induce T cell activation and suggest that HemoHIM-treated BMDCs may more effectively induce $\mathrm{T}$ cell responses against antigens.

TLR ligands are promising candidate immune stimulatory adjuvants for tumor-therapy [12] and have been reported to be expressed on APCs, including immune cells, and to be required for immune responses [54-56]. Moreover, TLR4 has been reported to induce Th1 responses in studies of immune adjuvants for tumor-therapy [54-56]. In the present study, co-stimulatory molecule expression and the amount of cytokines secreted by HemoHIMtreated BMDCs from TLR4 ${ }^{-1-}$ mice were decreased, while cytokine secretion by BMDCs from wild-type and HemoHIM-treated TLR2 ${ }^{-1-}$ mice were increased. Previous studies of a variety of immunoadjuvant plant extracts that function via $\mathrm{DC}$-mediated immune responses have focused on TLR4 agonists [10, 57, 58]. However, HemoHIM is an herbal mixture, and perhaps only one of its components is recognized by TLR4.

The present study demonstrates that HemoHIM induces the phenotypic and functional maturation of DCs, which initiate $\mathrm{T}$ cell responses, including specific-CD8 ${ }^{+}$ $\mathrm{T}$ cell responses and specific-CD4 Th1 responses, in a TLR-4 mediated manner. Also, we proved that HemoHIM enhances functional maturation of s-DCs by in vivo. HemoHIM in combination with cisplatin was previously reported to have anti-cancer effects in vitro and in vivo [31], and the present study suggests that these effects are due to the enhancement of $\mathrm{T}$ cell responses when DCs are treated with HemoHIM. Accordingly, our findings indicate that HemoHIM is a potential tumortherapy that enhances DC-based T cell responses.

\section{Conclusions}

In summary, our study demonstrated that HemoHIM induces TLR4-mediated BMDCs maturation. Furthermore, we showed the antigen-presenting ability that HemoHIM-treated mature BMDCs increase $\mathrm{CD}^{+}$and $\mathrm{CD}^{+} \mathrm{T}$ cell responses by in vitro. Therefore, HemoHIM has the potential dendritic cell-based immunoadjuvant.

\section{Abbreviations}

Abs: antibodies; APC: antigen presenting cell; BMDC: bone marrow-derived dendritic cell; BrdU: 5-Bromo-2 -Deoxy-Uridine; CCR: chemokine receptor 7; CD: cluster of differentiation; CFA: complete Freund s adjuvant;

CFSE: carboxyfluorescein succinimidyl ester; DC: dendritic cell; DW: distilled water; ELISA: enzyme-linked immunosorbent assay; FACS: fluorescence-activated cell sorting; FBS: fetal bovine serum; FITC: fluorescein isothiocyanate; GM-CSF: granulocyte-macrophage colony-stimulating facto; IFA: incomplete Freund s adjuvant; IFN: interferon; IL: interleukin; ip: intraperitoneal injection; LPS: lipopolysaccharide; MHC: major histocompatibility complex; MLR: mixedlymphocyte reaction; MMC: mitomycin C; OVA: ovalbumin; Pam3: pam3csk4; PBS: phosphate buffered saline; PE: phycoerythrin; PI: propidium iodide; S-DC: spleen-dendritic cell; TCR: T-cell receptor; Th: helper T cell;

TLR: toll-like receptor; TNF: tumor necrosis factor.

\section{Competing interests}

The authors declare that they have no competing interests.

\section{Authors' contributions}

SJL designed the study, performed all experiments and wrote the manuscript; JJK designed the experiments, contributed to manuscript preparation; KYK, YHH contributed to manuscript preparation and helped FACS analysis; GYJ helped ELISA analysis; SKJ, UHJ, HRP carried out making HemoHIM; STY conceived of the study and participated in its design. All authors have read and approved the manuscript.

\section{Acknowledgments}

This study was supported by the Suncheon Research Center for Natural Medicines in the Republic of Korea and by a grant from the Traditional Korean Medicine R\&D Project of the Ministry of Health \& Welfare in the Republic of Korea (H12C1893).

\section{Author details}

${ }^{1}$ Department of Pharmacy, Sunchon National University, 255 Joongang-Ro, Seokhyeon-Dong, Suncheon 549-742, Republic of Korea. ${ }^{2}$ Department of Chemistry, National University of Singapore, Singapore 117543, Singapore. ${ }^{3}$ Radiation Research Division for Bio-Technology, Advanced Radiation Technology Institute, Jeongeup Campus of Korea Atomic Energy Research Institute (KAERI), Jeongeup, Republic of Korea.

Received: 3 October 2015 Accepted: 12 February 2016

Published online: 19 February 2016

References

1. Li X, He X, Liu B, Xu L, Lu C, Zhao H, et al. Maturation of Murine Bone Marrow-Derived Dendritic Cells Induced by Radix Glycyrrhizae Polysaccharide. Molecules. 2012;17:6557-68.

2. Kim GY, Lee MY, Lee HJ, Moon DO, Lee CM, Jin CY, et al. Effect of water-soluble proteoglycan isolated from Agaricus blazei on the maturation of murine bone marrow-derived dendritic cells. Int Immunopharmacol. 2005;5:1523-32. 
3. English K, Barry FP, Mahon BP. Murine mesenchymal stem cells suppress dendritic cell migration, maturation and antigen presentation. Immunol Lett. 2008;115:50-8.

4. Steinman RM. The dendritic cell system and its role in immunogenicity. Annu Rev Immunol. 1991;9:271-96.

5. Banchereau J, Steinman RM. Dendritic cells and the control of immunity Nature. 1998;392:245-52.

6. Kawai T, Akira S. Pathogen recognition with Toll-like receptors. Curr Opin Immunol. 2005;17:338-44.

7. Liang J, Fu J, Kang H, Lin J, Yu Q, Yang Q. The stimulatory effect of TLRs ligands on maturation of chicken bone marrow-derived dendritic cells. Vet Immunol Immunopathol. 2013;155:205-10.

8. Cella M, Enqering A, Pinet V, Pieters J, Lanzavecchia A. Inflammatory stimuli induce accumulation of MHC class II complexes on dendritic cells. Nature. 1997:388:782-7.

9. Yoshida M, Mata J, Babensee JE. Effect of poly(lactic-co-glycolic acid) contact on maturation of murine bone marrow-derived dendritic cells. J Biomed Mater Res A. 2007;80:7-12.

10. Kim JJ, Hwang YH, Kang KY, Kim I, Kim JB, Park JH, et al. Enhanced dendritic cell maturation by the B-chain Korean mistletoe lectin (KML-B), a novel TLR4 agonist. Int Immunopharmacol. 2014;21:309-19.

11. Jung ID, Jeong SK, Lee CM, Noh KT, Heo DR, Shin YK, et al. Enhanced efficacy of therapeutic cancer vaccines produced by co-treatment with Mycobacterium tuberculosis heparin-binding hemagglutinin, a novel TLR4. Cancer Res. 2011;71:2858-70.

12. Unger WW, van Beelen AJ, Bruijns SC, Joshi M, Fehres CM, van Bloois $L$, et al. Glycan-modified liposomes boost $\mathrm{CD}^{+}$and $\mathrm{CD}^{+} \mathrm{T}$-cell responses by targeting DC-SIGN on dendritic cells. J Control Release. 2012;160:88-95.

13. Agrawal S, Agrawal A, Doughty B, Gerwitz A, Blenis J, van Dyke T, et al. Cutting edge: different Toll-like receptor agonists instruct dendritic cells to induce distinct Th responses via differential modulation of extracellular signal-regulated kinase-mitogen-activated protein kinase and c-Fos. J Immunol. 2003;171:4984-9.

14. Koido S, Homma S, Okamoto M, Namiki Y, Takakura A, Odahara S, et al. Combined TLR2/4-activated dendritic/tumor cell fusions induce augmented cytotoxic T-lymphocytes. PLos One. 2013;8:e59280.

15. Termeer C, Benedix F, Sleeman J, Fieber C, Voith U, Ahrens T, et al. Oligosaccharides of Hyaluronan activate dendritic cells via toll-like receptor 4. J Exp Med. 2002;195:99-111.

16. Rock FL, Hardiman G, Timans JC, Kastelein RA, Bazan JF. A family of human receptors structurally related to Drosophila Toll. Proc Natl Acad Sci U S A. 1998;95:588-93.

17. Poltorak A, He X, Smirnova I, Liu MY, Van Huffel C, Du X, et al. Defective LPS signaling in $\mathrm{C} 3 \mathrm{H} / \mathrm{HeJ}$ and $\mathrm{C} 57 \mathrm{BL} / 10 \mathrm{ScCr}$ mice: mutations in Tlr4 gene. Science. 1998;282:2085-8.

18. Lien E, Means TK, Heine H, Yoshimura A, Kusumoto S, Fukase K, et al. Toll-like receptor 4 imparts ligand-specific recognition of bacterial lipopolysaccharide. J Clin Invest. 2000;105:497-504.

19. Rescigno M, Granucci F, Citterio S, Foti M, Ricciardi-Castagnoli P. Coordinated events during bacteria-induced DC maturation. Immunol Today. 1999;20:200-3.

20. Hou B, Benson A, Kuzmich L, DeFranco AL, Yarovinsky F. Critical coordination of innate immune defense against Toxoplasma gondii by dendritic cells responding via their Toll-like receptors. Proc Natl Acad Sci U S A. 2011;108:278-83.

21. Kim JJ, Choi J, Lee MK, Kang KY, Pail MJ, Jo SK, et al. Immunomodulatory and antidiabetic effects of a new herbal preparation (HemoHIM) on streptozotocin-induced diabetic mice. Evid Based Complement Alternat Med. 2014;2014:461685.

22. Jo SK, Lee HJ, Kim SR, Kim JC, Bae CS, Jung U, et al. Antiinflammatory activity of an herbal preparation (HemoHIM) in rats. Phytother Res. 2007;21:625-8.

23. Kim JJ, Jo SK, Jung UH, Park HR, Yee ST. Inhibitory effects of a herbal composition (HemoHIM) on the activation of human mast cell line (HMC-1). J Life Sci. 2009:19:1808-14.

24. Park HR, Jo SK, Jung U, Yee ST. Restoration of the immune functions in aged mice by supplementation with a new herbal composition, HemoHIM. Phytother Res. 2008;22:36-42.

25. Park HR, Jo SK, Choi NH, Jung U. HemoHIM ameliorates the persistent down-regulation of Th1-like immune responses in fractionated -irradiated mice by modulating the IL-12p70-STAT4 signaling pathway. Radiat Res. 2012;177:676-84
26. Kim SH, Lee HJ, Kim JS, Moon C, Kim JC, Park HR, et al. Protective effect of an herbal preparation (HemoHIM) on radiation-induced intestinal injury in mice. J Med Food. 2009;12:1353-8.

27. Kim JJ, Jo SK, Jung U, Park HR, Yee ST. Inhibitory effect of a new herbal composition (HemoHIM) on UVB-induced suppression of langerhans cell s accessory cell function. J Life Sci. 2006;21:1761-71.

28. Park HR, Jo SK, Jung U, Kim SH, Yee ST. Immunomodulatory effect of a new herbal preparation (HemoHIM) in cyclophosphamide-treated mice. J Food Sci Nutr. 2006;11:54-60.

29. Park HR, Kim SH, Yee ST, Byun MW, Jo SK. Effect of a herbal mixture (HIM-1) on the protection of the hematopoietic-immune system and self-renewal tissues against radiation damage. J Korean Soc Food Sci Nutr. 2005;34:605-12.

30. Jo SK, Park HR, Jung U, Oh H, Kim SH, Yee ST. Protective effect of a herbal preparation (HemoHIM) on the self-renewal tissues and immune system against r-irradiation. J Korean Soc Food Sci Nutr. 2005;34:805-13.

31. Park HR, Ju EJ, Jo SK, Jung U, Kim SH, Yee ST. Enhanced antitumor efficacy of cisplatin in combination with HemoHIM in tumor-bearing mice. BMC Cancer. 2009;9:85.

32. Kim JJ, Cho HW, Park HR, Jung U, Jo SK, Yee ST. Preventative effect of an herbal preparation (HemoHIM) on development of airway inflammation in mice via modulation of Th1/2 cells differentiation. PLos One. 2013;8:e68552.

33. Jo SK, Jung UH, Park HR. Development of special medical foods and botanical drugs using HemoHIM for cancer patients during radiation therapy. Research report NO. KAERI/RR-2998/2008, Korea Atomic Energy Research Institute, 2010.

34. Park HR, Jo SK, Jung U, Yee ST, Kim SH. Protective effects of HemoHIM on immune and hematopoietic systems against -irradiation. Phytother Res. 2014;28:245-51.

35. Kadaoui KA, Corthesy B. Isolation of dendritic cells from mouse Peyer s patches using magnetic cell sorting. MACS\&more. 2004;8:10-2.

36. Krajina $T$, Leithauser $F$, Moller $\mathrm{P}$, Trobonjaca Z, Reimann J. Colonic lamina propria dendritic cells in mice with $\mathrm{CD}^{+} \mathrm{T}$ Cell-induced colitis. Eur J Immunol. 2003;33:1073-83.

37. Hou WS, Van Parijis L. A BCl-2-dependent molecular timer regulates the lifespan and immunogenicity of dendritic cells. Nat Immunol. 2004:5:583-9.

38. Swanson KA, Zheng Y, Heidler KM, Zhang ZD, Webb TJ, Wilkes DS. Flt3-Ligand, II-4, GM-CSF, and adherence-mediated isolation of murine lung dendritic cells: assessment of isolation technique on phenotype and function. J Immunol. 2004;173:4875-81.

39. Johansson C, Wick MJ. Liver dendritic cells present bacterial antigens and produce cytokines upon Salmonella Encounter. J Immunol. 2004;172:2496-503.

40. Heufler C, Koch F, Schuler G. Granulocyte/macrophage colony-stimulating factor and interleukin 1 mediate the maturation of murine epidermal Langerhans cells into potent immunostimulatory dendritic cells. J Exp Med. 1988;167:700-5

41. Means TK, Hayashi F, Smith KD, Aderem A, Luster AD. The Toll-like receptor 5 stimulus bacterial flagellin induces maturation and chemokine production in human dendritic cells. J Immunol. 2003:170:5165-75.

42. Kamath A, Pooley J, O Keeffe MA, Vremec D, Zhan Y, Lew AM, et al. The development, maturation, and turnover rate of mouse spleen dendritic cell populations. J Immunol. 2000;165:6762-70.

43. Boonstra A, Asselin-Paturel C, Gilliet M, Crain C, Trinchieri G, Liu YJ, et al. Flexibility of mouse classical and plasmacytoid-derived dendritic cells in directing T helper type 1 and 2 cell development: dependency on antigen dose and differential toll-like receptor ligation. J Exp Med. 2003;197:101-9.

44. Trinchieri G. Interleukin-12 and the regulation of innate resistance and adaptive immunity. Nat Rev Immunol. 2003;3:133-46.

45. Kim JJ, Nam JP, Nah JW, Jang MK, Yee ST. Immunoadjuvant efficacy of $\mathrm{N}$-carboxymethyl chitosan for vaccination via dendritic cell activation. J Med Food. 2013;17:268-77.

46. Kanto T, Kalinski P, Hunter OC, Lotze MT, Amoscato AA. Ceramide mediates tumor-induced dendritic cell apoptosis. J Immunol. 2001;167:3773-84.

47. Zeid NA, Muller HK. S100 positive dendritic cells in human lung tumors associated with cell differentiation and enhanced survival. Pathology. 1993;25:338-43.

48. Tsuge T, Yamakawa M, Tsukamoto M. Infiltrating dendritic/Langerhans cells in primary breast cancer. Breast Cancer Res Treat. 2000;59:141-52.

49. Kim JY, Yoon YD, Ahn JM, Kang JS, Park SK, Lee K, et al. Angelan isolated from Angelica gigas Nakia induces dendritic cell maturation through toll-like receptor 4. Int Immunopharmacol. 2007;7:78-87. 
50. Kim GY, Oh WK, Shin BC, Shin Yl, Park YC, Ahn SC, et al. Proteoglycan isolated from Phellinus linteus inhibits tumor growth through mechanisms leading to an activation of CD11 $\mathrm{C}^{+} \mathrm{CD}^{+} \mathrm{DC}$ and type I helper T cell-dominant immune state. FEBS Lett. 2004;576:391-400.

51. Kim HM, Han SB, Oh GT, Kim YH, Hong DH, Hong ND, et al. Stimulation of humoral and cell mediated immunity by polysaccharide from mushroom Phellinus linteus. Int J Immunopharmacol. 1996;18:295-303.

52. Hua H, Liang Z, Li W, Meng Y, Li X, Zhang Z, et al. Phenotypic and functional maturation of murine dendritic cells (DCs) induced by purified Glycyrrhizin (GL). Int Immunopharmacol. 2012;12:518-25.

53. Gourgiotis D, Papadopoulos NG, Bossios A, Zamanis P, Saxoni-Papageorgiou P. Immune modulator pidotimod decreases the in vitro expression of CD30 in peripheral blood mononuclear cells of atopic asthmatic and normal children. J Asthma. 2004;41:285-7.

54. Li S, Lin YC, Ho CT, Lin PY, Suzama M, Wang HC, et al. Formulated extract from multiple citrus peels impairs dendritic cell functions and attenuates allergic contact hypersensitivity. Int Immunopharmacol. 2014;20:12-23.

55. Granucci F, Zanoni I. Role of Toll like receptor-activated dendritic cells in the development of autoimmunity. Front Biosci. 2008;13:4817-26.

56. Takeuchi O, Hoshino K, Kawai T, Sanjo H, Takada H, Ogawa T, et al. Differential roles of TLR2 and TLR4 in recognition of gram-negative and gram-positive bacterial cell and wall components. Immunity. 1999;11:443-51.

57. Zhou Z, Lin J, Huo R, Huang W, Zhang J, Wang L, et al. Total glucosides of paeony attenuated functional maturation of dendritic cells via blocking TLR4/5 signaling in vivo. Int Immunopharmacol. 2012;14:275-82.

58. Huang $D$, Nie $S$, Jiang $L$, Xie M. A novel polysaccharide from the seeds of Plantago asiatica L. induces dendritic cells maturation through toll-like receptor 4. Int Immunopharmacol. 2014;18:236-43.

\section{Submit your next manuscript to BioMed Central and we will help you at every step:}

- We accept pre-submission inquiries

- Our selector tool helps you to find the most relevant journal

- We provide round the clock customer support

- Convenient online submission

- Thorough peer review

- Inclusion in PubMed and all major indexing services

- Maximum visibility for your research

Submit your manuscript at www.biomedcentral.com/submit 